actions," it may possibly be the author's intention to append them to a future communication to the Royal Society, in continuation of other important papers already published in the "Transactions,"-a place which the Tables will advantageously occupy. They give with sun's longitude as argument, the inclination of the solar axis to the circle of declination, reckoned positive when the axis is west of the north point of the sun's disc, and assuming the inclination of his equator to the ecliptic to be $7^{\circ} 15^{\prime} \circ$, and the longitude of its ascending node $74^{\circ}-\nu$; and with argument, sun's longitude $+\nu$, the "Heliographical latitude of the earth" and "Reduction of longitude." The obliquity of the ecliptic is taken, $23^{\circ} 27^{\prime} .5$, but to correct the angle between the circle of declination and the sun's axis, for difference of true and assumed obliquity, a supplementary table is provided.

The Tables have been calculated by Mr. Marth, and it will be obvious to anyone initiated in such work, that considerable trouble has been taken to ensure their accurate production,

MIRA CETI.-A minimum of this variable star is set down in Schönfeld's ephemeris for September 3o. The minima have not been properly observed nearly so often as the maxima, though equally important in the investigation of the laws which regulate the fluctuations of light, and which, according to Argelander's researches, involve a more complicated formula than has yet been deduced for any other variable. The circumstances of the approaching minimum are very favourable for observation.

\section{SCIENCE IN GERMANY}

(From a German Correspondent.)

$\mathrm{O}^{\mathrm{N}}$ LV for a small number of elements and their compounds is the relatively low temperature of the nonluminous gas flame sufficient to produce spectra which can be of use in analy tical researches; by far the larger number turn into vapour at such degrees of temperature as we can obtain solely by the electric spark. We are therefore confined to spark spectra for such bodies which do not give spectra in the flame, and these spark spectra can all the less be dispensed with in those cases where new elements are songht for, or where it is a question of proving beyond all doubt the presence of certain bodies, which in their chemical properties are so much alike that ordinary reagents do not suffice for their discovery or separation.

But there are difficulties in the way of practically using spark spectra, which have been the reason why these important means of reaction have not yet found their entry into all chemical laboratories. First of all, a simple method has been wanting by which spark spectra can be obtained at any time. Whoever has been obliged to use currents of great intensity with temporary interruptions of days, weeks, or months, knows how much unpleasantness is caused by fitting, taking to pieces, and cleaning the ordinary constant batteries used hitherto, Another difficulty lies in the fact that spectrum tables are still wanting which would be of sufficient service for all practical purposes. It is true that a large quantity of measurements have been published, and doubtless some of them are extremely accurate, but with the greatest part of them the purity of the substances experimented with is not in the least guaranteed, and very often it can be proved not to have been attended to at all. If it is attempted to reduce to a universal scale all the spectrum drawings at hand which have been obtained by different observers, with different refractive media, with different widths of the slit, some at a higher, and some at a lower temperature, tables are obtained which are completely and utterly useless in the laboratory.

Lately Prof, Bunsen, of Heidelberg, has tried to remove all these difficulties. In a very important treatise, the first part of which has just been published, he first describes a new battery and a new spark apparatus, by means of which spark spectra can at any time be obtained with the same ease and facility as ordinary flame spectra. The battery is the charcoal-zinc battery without clay cells. The exciting liquid is a mixture of bichromate of potash and sulphuric acid. In order to prepare ro litres of this liquid, Prof. Bunsen gives the following instructions :0.765 kilogrammes of commercial powdered bichromate of potash, which as a rule contains about 3 per cent. of impurities, are mixed with 0.832 litres of sulphuric acid in a stone jar while the mass is being constantly stirred; when the salt is changed to sulphate of potash and chromic acid, 9.2 litres of water are added, the stirring being kept up and the water allowed to flow from a spout about $\frac{1}{2}$ inch wide; the crystal meal, which already is very warm, thus gets warmer and warmer and eventually dissolves completely. The exciters for this liquid are : a rod of the densest gas coal, $4 \mathrm{~cm}$. broad, I $3 \mathrm{~cm}$. thick, and immersed $\mathrm{i} 2 \mathrm{~cm}$. deep in to the liquid, and a rolled plate of zinc $4 \mathrm{~cm}$. broad, $0.5 \mathrm{~cm}$. thick, and immersed to the same depth as the coal; the zinc plate is entirely coated with a layer of wax (which is put on whilst hot), except that plane which is turned towards the coal and which is amalgamated. The distance between coal and zinc is entirely optional; in the spectral and analytical researches of Prof. Bunsen it varied according to circumstances between 3 and Io millimetres. The results with this battery are, however, not very satisfactory with regard to duration and constancy of current, if the cell containing the exciting liquid is made of the same size and shape as those in the ordinary Grove or Bunsen battery. The reason of this lies in the circumstance that in the nitric acid of those batteries there is far more oxygen contained, which is employed for depolarisation, than in an equal weight of the chromate liquid, and that therefore a comparatively much larger quantity of the latier is used up to obtain the same effect. The chromic acid battery therefore, compared to Grove's battery, requires cells of at least three to four times more capacity. The best shape for these cells is that of narrow, high cylinders. The column of liquid, of about $x$ ' 6 litres, has a diameter' of about $0^{\circ} 088$ metres, and stands $0^{\circ} 28$ metres high in the cylinder, which bears a mark at that height. The zinccoal pair is only immersed up to half its height into the liquid column, and has an active zinc surface of about forty-eight square $\mathrm{cm}$.

With regard to the constants of this chromic acid battery without clay cells, it considerably suxpasses in electromotive force all other apparatus with clay cells hitherto used. It possesses an electromotive force which is about 13 per cent. larger than the ordinary charcoal-zinc Grove battery. Its essential conduction resistance is about 12 per cent. smaller than that of Grove's batrexy with clay cells. In order to be able to judge the econo.. mical effect of the chromic acid battery, we will consicler a little more in detail the chemical processes taking place in this battery. In unconnected freshly filled Grove batteries the consumption of zinc is very small, only when after prolonged use an electrolytic and endosmotic exchange has taken place between the two exciting liquids, a consumption of zinc, independent of the generation of the current, becomes apparent. In the unconnected chromic acid battery, however, the consumption of zinc at the very beginning is entirely the same as that which is observed in connected batteries during the generation of the current. This circumstance makes is indispensable to arrange the chromic acid battery in such a manner as to make it easy, at every interruption of the current, to bring the exciting plates out of contact with the liquid. This is attained by a simple hand lever arrangement by which the plates can be dipped into or raised out of the liquid. It is of particular interest, not 
only for practical purposes, but also from a theoretic point of view, to compare the consumption of zinc during the generation of the current with that in the unconnected battery, as theory alone gives no basis on which to decide the question whether the zinc disssolved in the unconnected battery is entirely, partly, or not at all used in the connected battery for the generation of the current. Investigation showed that the quantity of zinc dissolved in the disconnected battery is a little under half of the consumption of zinc necessary acording to theory to generate the current in the connected battery, and that only a part of the metal dissolved in the disconnected battery without current-generation is used up in the connected one for the generation of the current. This fact entirely corresponds with the view that the dissolution of the zinc must not be looked upon as the cause of the current, but as a necessary condition of the same. Investigation further showed that while in the chromic acid battery above described, on the average only 22 per cent. of zinc was lost, the loss in the nitric acid battery experimented with was 48 per cent. on the average. The chromic acid battery without clay cells is the least constant one amongst the ordinary constant batteries. But if used in a proper manner it may serve for a very long time. Prof. Bunsen possesses a battery of this kind, of forty pairs, with an active zinc surface on each plate of only forty square $\mathrm{cm}$. For the last eight lecture-terms it has served for all experiments without its having been necessary during this long time to renew the zinc plates, or their coatings of wax, or the original exciting liquid, nor to clean the conducting connection parts; it has been merely necessary to renew now and then the amalgamation of the zinc plates (an operation which only takes a few minutes of time) and to replace that part of the liquid which was lost by evaporation in the air, by simply filling the cylinders with water up to the marks on their sides. The apparatus to this day still gives an electric arc between carbon points which amply suffices for the photo-chemical lecture experiments. The currents obtained by this battery, which has now been in use for already more than four years, are still powerful enough for demonstrations in electrolysis, spark spectra, decomposition of gases by induction sparks, $\& c$, and will doubtless continue to suffice for all these purposes for some time to come. But we must again repeat that effects of such magnitude can only be expected if the precaution is used (and it is very easy to do so) not to leave the pairs in contact with the liquid for one moment longer than the duration of the current necessary for the experiments requires it.

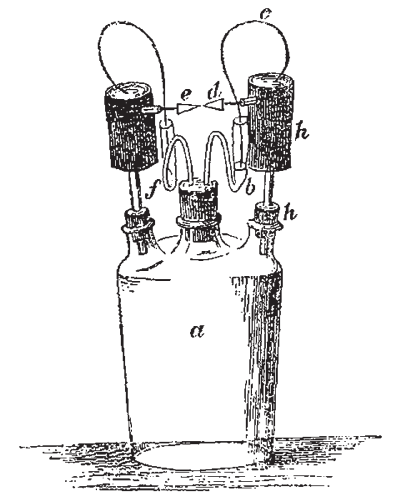

The battery used for the production of spark spectra consists of four of the pairs above described. The pole wires conduct the primary current, of which a branch puts the current interruptor into action, to a Ruhmkorff apparatus, the induction coil of which has a diameter of nearly $0^{\prime} 2$ metres and a length of $0^{\prime} 5$ metres. The cur- rent induced in the same is conducted to the spark apparatus, standing in front of the slit of the spectroscope : $a$, a bottle with three necks, serves as a stand for the spark apparatus. The induced current goes from the inercury cup $b$, through the fine wire $c$ to the carbon point $d$, which is fastened on a pointed platinum wire; thence it passes as a spark to the other carbon point $e$, and from this it reaches the second mercury cup $f$, which is connected with the other end of the induction coil. The platinum wires, which are surrounded by glass tubes sealed firmly upon them, can be moved upwards or downwards by the corks $h$, and this allows of a quick and exact fixing of the carbon points before the slit of the spectroscope.

The carbon points destined to receive the little quantities of liquids under examination are best prepared from the ordinary and not too light drawing charcoal, which is easily procurable. In order first to impart conducting power to the charcoal, a great number of the sticks are exposed to the most intense white heat for some time in a covered porcelain crucible, which stands in a larger clay crucible, and is on all sides surrounded by charcoal powder. Then the sticks are cut to points at one end, and the little charcoal cone thus obtained is cut off with a fine watchmaker's saw, In order to remove the silica, magnesia, manganese, iron, potash, soda, and lithia which the charcoal contains, about a thous and of the points are boiled in a platinum dish, first with hydrofluoric acid, then with concentrated sulphuric acid, then with concentrated nitric acid, and finally with hydrochloric acid, repeating each process several times, while between each manipulation each of the acids is removed by washing and boiling with water. After this treatment the carbon points are ready for use. A carbon cone of this description weighs about o*or 5 grammes, and can absorb more than its own weight of liquid. The spark spectra obtained by aid of them are of very long duration.

We will report on the second part of Prof. Bunsen's treatise as soon as it has been published.

W.

HISTORICAL NOTE ON THE OBSERVATION OF THE CORONA AND RED PROMINENCES

OF THE SUN*

SO much interest attaches to the phenomena of the corona and red prominences, as observed during total solar eclipses, and correct views of their nature and of the proper means of observing them are so recent, that I feel it proper to give here a brief account of what I believe to be the first attempt to see these, under ordinary conditions, with an uneclipsed sun. $t$ This account is contained in the private diary of the late G. P. Bond, formerly director of the Observatory of Harvard College, which has become known to me through the kindness of his daughters.

Bond observed the total solar eclipse of July 28, $185 \mathrm{I}$, at Lilla Edet in Sweden, and his report is published in the Memoirs of the Royal Astronomical Society, vol. xxi., p. 97 .

From Sweden, Bond went to Geneva, where he arrived in September $185 \mathrm{I}$, and from this point I may transcribe from his diary, making no changes except the occasional insertion or omission of unimportant words.

"Geneva, Sunday, Sept. I4, I 85 1.- I think I must go to Chamounix to try whether it may be possible to discern the red flames on the sun's disc by occulting all but the very edge, upon one of the lofty peaks. It seems to me not altogether impossible. Certainly an experiment worth trying and a new application of the 'Aiguilles.' . . .

"Geneva, Sept. 15, 1851. . . . The weather looks dark and lowering, with an uncomfortable north-east

* By Edward S. Holden. Reprinted from the August number of the American Fournal of Science.

$t$ Airy, Nasmyth, Baden-Powell, Piazzi-Smyth, and others experimented in this direction, about this time, with various results. See Edinburgh Ast. Obs., vol. xi. p, 279; Mem. R. A. S., vol. xvi. p. 301, \&c. 